\title{
Synthesis, Characterization and Electrical Conductivity of Nano-Crystalline Erbium Sesquioxide by the Precipitation Method and Subsequent Calcination
}

\author{
Bahaa M. Abu-Zied ${ }^{1,2, *}$,Mahmoud A. Hussein ${ }^{2}$, Abdullah M. Asiri ${ }^{1,2}$ \\ ${ }^{1}$ Center of Excellence for Advanced Materials Research (CEAMR), King Abdulaziz University, P.O. \\ Box 80203, Jeddah 21589, Saudi Arabia \\ ${ }^{2}$ Chemistry Department, Faculty of Science, King Abdulaziz University, P.O. Box 80203, Jeddah \\ 21589, Saudi Arabia \\ *E-mail: babuzaid@kau.edu.sa
}

doi: $10.20964 / 2016.08 .61$

Received: 28 April 2016 / Accepted: 15 June 2016 / Published: 7 July 2016

Due to its superior properties, erbium sesquioxide, $\mathrm{Er}_{2} \mathrm{O}_{3}$, is considered as an important material for applications in various fields such as corrosion-resistant coating, electrical insulating coating, in sensing membranes, semiconductor devices, as catalyst, and for applications in nuclear engineering. In the open literature there is a lack of information about the preparation of $\mathrm{Er}_{2} \mathrm{O}_{3}$ nanoparticles using the homogenous precipitation and subsequent calcination route. In this paper a facile method for the synthesis of $\mathrm{Er}_{2} \mathrm{O}_{3}$ nanoparticles is suggested. The fabrication was carried out by using the homogeneous precipitation of an erbium ions using sodium hydroxide followed by the calcination process. The influence of: (i) the $\mathrm{pH}$ value (9-12) during precipitation process, and (ii) the calcination temperature $300-700{ }^{\circ} \mathrm{C}$ on the structural and textural properties of the solids obtained will be addressed. The thermal events accompanying the heat treatment of the dried parent was monitored using thermogravimetric analysis (TGA). Various physicochemical techniques were used for investigating the structure and morphology of $\mathrm{Er}_{2} \mathrm{O}_{3}$ nanoparticles. These include X-ray diffraction (XRD), Fourier transform infrared (FTIR) spectra, filed emission scanning electron microscopy (FESEM), transmission electron microscopy (TEM), and X-ray photoelectron spectroscopy (XPS). Moreover, the electrical conductivity of the calcined samples with temperature was measured.

Keywords: nanocrystalline erbium oxide; $\mathrm{Er}_{2} \mathrm{O}_{3}$; erbium sesquioxide, electrical conductivity, precipitation method; $\mathrm{Er}_{2} \mathrm{O}_{3}$ nanoparticles

\section{FULLTEXT}


(C) 2016 The Authors. Published by ESG (www.electrochemsci.org). This article is an open access article distributed under the terms and conditions of the Creative Commons Attribution license (http://creativecommons.org/licenses/by/4.0/). 